\title{
TOWARDS DEVELOPING AN ECOLOGICAL TOURISM SETTLEMENT IN SIWA OASIS, EGYPT: CASE STUDY OF BABENSHAL ECO-LODGE
}

\author{
OLA ALI BAYOUMI ${ }^{1}$, MOHAMED ABDELALL ${ }^{2} \&$ MOHAMED ANWAR FIKRY ${ }^{2}$ \\ ${ }^{1}$ Department of Architecture, Alexandria University, Egypt \\ ${ }^{2}$ Alexandria University, Egypt
}

\begin{abstract}
This paper is aiming to revive the real meaning of an "Eco-lodge" in the Egyptian western desert. Siwa was a totally isolated oasis centered at the North of Sahara desert and connected to the Egyptian Western desert, and thus it has a unique environmental features developed for thousands of years ago. Unfortunately, the new roads established by the Egyptian government to connect between Siwa oasis, Matrouh and Giza cities lead to the transformation of lots of new ideologies and innovative building materials. Beside the previous obstacles, foreign architects ignore most of the building strategies and restrictions created by local residence during establishing new "Siwan-tourism settlements." According to Dr. Emad's words, the designer of Babenshal eco-lodge, Siwan builders exchange their experience to future generations in order to respect Nature; the reason is they are totally aware that Nature's punishment is totally destructive and this is the truth that most architects forget about. For that the researcher will try to continue their research on giving a sample weighting for any future eco-lodges that are or will be built in Siwa oasis. According to their previous paper under the name "Developing an Ecological Assessment Tool for Siwan eco-lodges in the Egyptian Western Desert (EWD)" the researcher had created a criterion specified for local Siwan eco-lodges giving weighting coefficient values for Environmental and Social items, indicators and their parameters. By field work study and the usage of air quality multi-meter device they can find the mean value of the highest three indicators of IEQ which are $\mathrm{CO}_{2}$ in ppm, temperature in degree Celsius and air flow in $\mathrm{m} / \mathrm{s}$, multiplying them with their weighting coefficient $=0.14$. This method will be applied on one of the most famous eco-lodges "Babenshal Eco-lodge" as a case study to scientifically rate its environmental indoor quality.

Keywords: air quality measurements, ethnographic approach, Babenshal eco-lodge, Siwa oasis.
\end{abstract}

\section{INTRODUCTION}

Siwa oasis is the heart of the Egyptian western desert. It has a completely isolated culture and unique topographical features, the first is due to the different cultures that passed through it without sustaining their existence starting from the old Egyptians, Romans, and Greeks and ended with the Islamic conquest and the "Amazigh," while the second is due to its location where it locates in between 15 and $20 \mathrm{~m}$ below sea level and surrounded by high lands with the height 30 to $40 \mathrm{~m}$ above sea level [1]. On other hand its geological lands are concentrated by highly salty soil and shallow saline lacks that are used for medical purposes. Although the high salinity of the soil, it is so reach with minerals and mud that help palm trees to grow up (see Figs 1 and 2).

All of these features created unique architectural characteristics for Siwan lodges. Siwans in return respects Nature and fortune their private life. On other hand their Social life has a direct impact on creating those unique Siwan buildings to serve their "Indoor life quality"; this is because the harsh environmental characteristics as the oasis locate in the heart of the Egyptian western dry desert. After the researchers multiple visits to understand all those above features, they noticed the extreme and dangerous changes that happened to Siwan ecolodges over the last 10 years. And thus, they decided to continue developing their research to calculate the values of the highest environmental aspects indicators of their previous research 


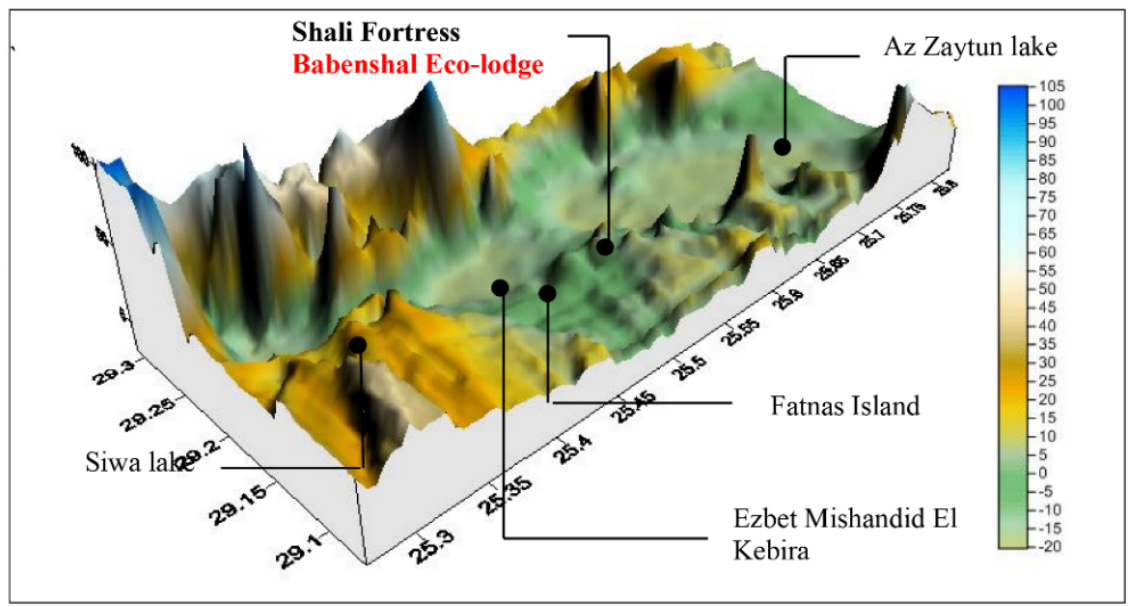

Figure 1: Topographical perspective of Siwa oasis. (Source: Authors.)

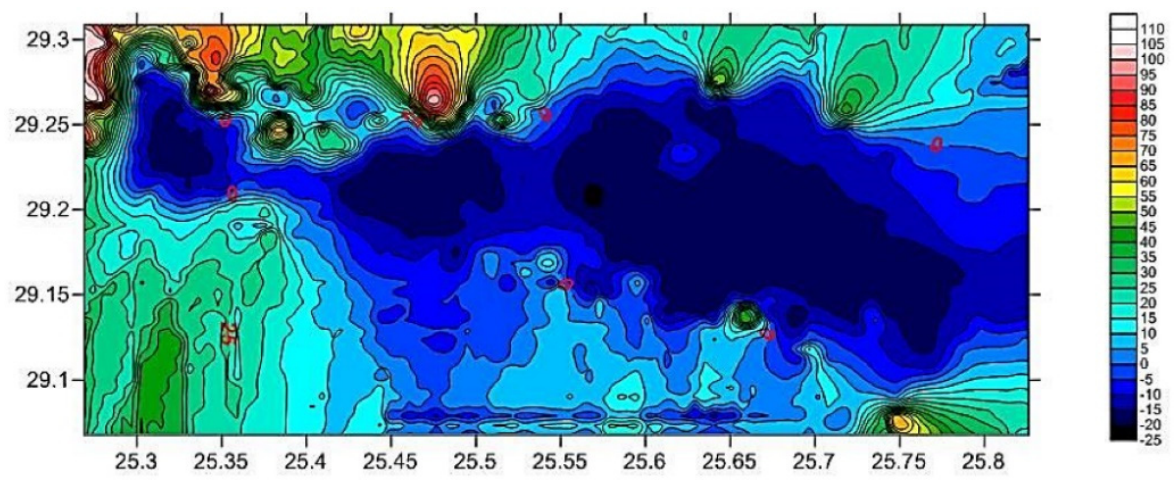

Figure 2: Topographical map of Siwa oasis. (Source: Authors.)

which are (life quality/ $\mathrm{CO}_{2}$, thermal comfort/Temperature and Ventilation quality/Air flow). Those values will be multiplied with their previous-established weighting coefficient $=0.14$ that is built for only Siwan eco-lodges [2] and the result will be the environmental rating of the Babenshal eco-lodge. This method is a key method that can be used to measure any Siwan eco-lodge's IEQ.

Moreover, those environmental aspects indicators have been chosen by Babenshal's designer and its construction engineer during their interview with the researchers. This interview has been recorded and transformed into a written index to show their opinion on the way in which Siwan eco-lodges should be developed [3].

\section{SIWAN ECO-LODGE DEVELOPMENT}

Siwan eco-lodges are the key-projects and the clear image that reflects Siwan culture and their architectural unique features. Due to economic, political and limited environmental variations, the main properties of Siwan accommodation and EWD Eco-lodges in specific have significantly been changed [4]. 
According to Table 1, Siwan eco-lodges have been changed in their size, way of construction and the distribution of internal spaces and those variables have been connected to the different locations and the construction method they are related to. However each case carries its pros and cons, but unfortunately the recently developed eco-lodges where related to the short term benefits. According to Dr. Emad words; "Due to the invasion of new chemical materials in the oasis, lots of local labors lost their mechanism and their experience in how to build with local provisions and lots of them already had stopped using their traditional techniques in their buildings and thus it was essential to encourage people financially and scientifically to build in their old ways" [3].

Table 1: A comparison shows the significant variations happened to Siwan eco-lodges since the beginning of its establishment till now. (Source: By the researcher.)






\section{RESEARCH METHOD FOR MEASURING ENVIRONMENTAL QUALITIES OF FUTURE BUILT ECO-LODGES}

\subsection{Indicating the highest items}

This research will try to use the "how method" to measure the highest two items and their maximum indicators that had been valued in the "What method" see Table 1 and Fig. 4, and had been indicated by professionals (Babenshal designer and its construction engineer) during their structural interview with the researcher. Those items are the indoor environmental quality and its relation to the site. The "how method" is done by using work field study and its aim is to insure the quality and the accuracy of the results.

Table 2: The second highest environmental items. (Source: The researchers in the paper "Developing an Ecological Assessment Tool for Siwan eco-lodges in the Egyptian Western Desert (EWD)”.)

\begin{tabular}{|l|l|c|}
\hline Items & \multicolumn{1}{|c|}{ Assessment categories } & Their weights \\
\hline $\mathrm{S}$ & Site & 0.14 \\
\hline $\mathrm{E}$ & Energy efficiency & 0.288 \\
\hline $\mathrm{W}$ & Water efficiency & 0.066 \\
\hline $\mathrm{M}$ & Material & 0.275 \\
\hline IEQ & Indoor environmental quality & 0.14 \\
\hline W\&P & Waste and pollution & 0.067 \\
\hline E\&C & Economic and cost & 0.025 \\
\hline
\end{tabular}

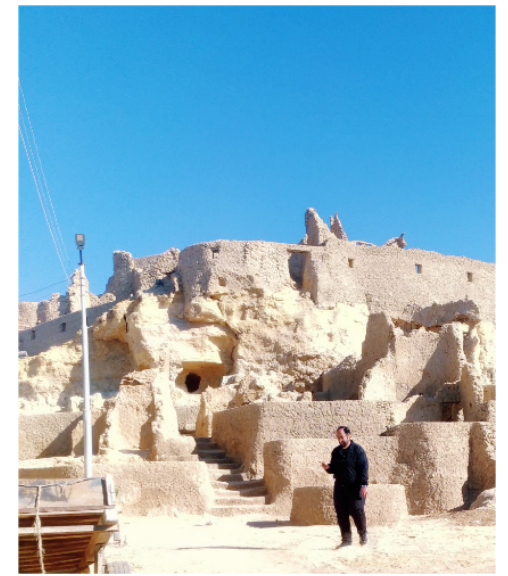

Figure 3: The researcher visiting Babenshal eco-lodge for field work study. (Source: Authors.)

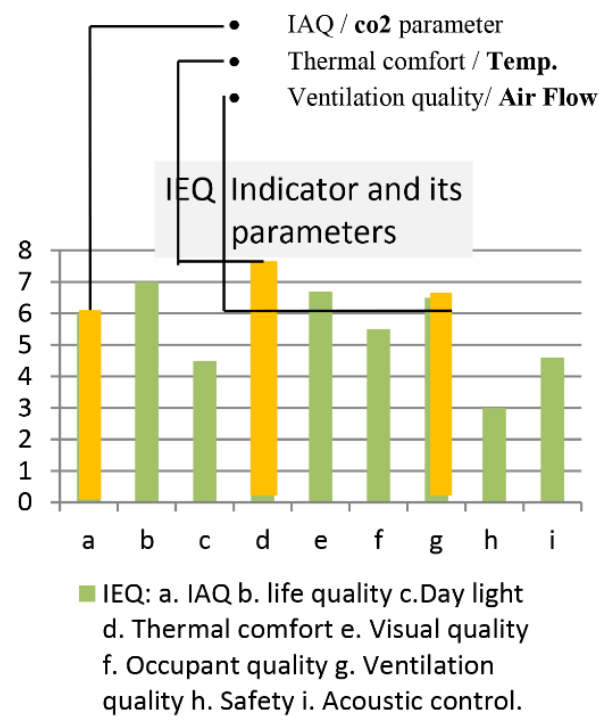

Figure 4: IEQ highest indicators (IAQ/CO ${ }_{2}$, thermal comfort/ temp, ventilation quality/air flow). (Source: Authors.) 


\subsection{Questionnaire contribution}

Engineer Emad Farid (the Architect), Eng. Ramiz Azmi (the construction engineering) and Raies Abdalla Hamoda (Siwan Builder of the lodge).

\subsection{Questionnaire structure}

The Questionnaire structure was summarized as the following: At first, the researchers tried to understand the criteria took by the architect and the construction engineering during developing their project (Babenshal eco-lodge), so they started asking about the site obstacles and what are the main criteria took in order to choose the target project location? According to Eng. Emad; in the past local people used to build on high lands in order to overcome the underground water humidity, but recently it is not an obstacle. However, architects must comprehend the nature of the project lands with the help of local labors and scientists must respect local builders experience and provide them with scientific knowledge respectively. Then the second question was based on the nature of the material that should be used in all design process and whether there is any contribution of advanced building materials to the traditional Kershef substance?

Dr. Emad answer was that Kershef material made of mud straw and salt is an excellent choice and perfect substance for isolation of sound, heat during summer and cold during winter, but the idea is that eco-lodges built with Kershef need large land space compared to contemporary eco-lodges, moreover, although environmental material's life cycle is not long as chemical materials, finishing materials made of white mud as shown in Babenshal lodge is more durable and can stay much longer than chemical pastes that should be renewed annually, on other hand, according to various scientific researches, chemical constructing materials have multiple negative health impact on humans. Then Eng. Ramis added "There are environmental solutions that can solve the pros related to this traditional material as using olive leaves to reduce cracks exist several years after the eco-lodge is constructed" then he added "A good example for this is Shali lodge that is built of raw Siwan rocks since 22 years ago and no cracks have appeared till now" [3]. Finally the questionnaire was ended by asking whether there is a criterion developed by officials or by the Government to control the system of new or previous established Siwan-lodges.

Eng. Emad said: "of course we need to build our own criteria for building any eco-lodge in Siwa oasis, we have already talked to coordinating system here to build one to make the concept of Environmental Eco-lodge in Siwa real. This system will aim to preserve the inheritance and construction coordination of the oasis on both building and urban scales" [3].

\subsection{Field work study: Babenshal eco-lodge}

\subsubsection{Coding tracing points for Babenshal internal spaces}

As an initial step, the researcher had to code the most usable internal spaces. The Ground floor has the codes starting with (IT = Restaurant) and (IR = open courtyard), the First floor has the codes starting with ( $\mathrm{FC}=$ cafeteria and sitting area) and the Second floor has the codes starting with $(\mathrm{RO}=$ Roof Restaurant) (see Fig. 5).

\subsection{2 $\mathrm{CO}_{2}$ tracing points in ppm}

By using $\mathrm{CO}_{2}$ measuring tool in the field/Babenshal eco-lodge depending on the codes given in Fig. 6, the researcher found that the first floor restaurant carries the highest $\%$ of $\mathrm{CO}_{2} \mathrm{ppm}$ 


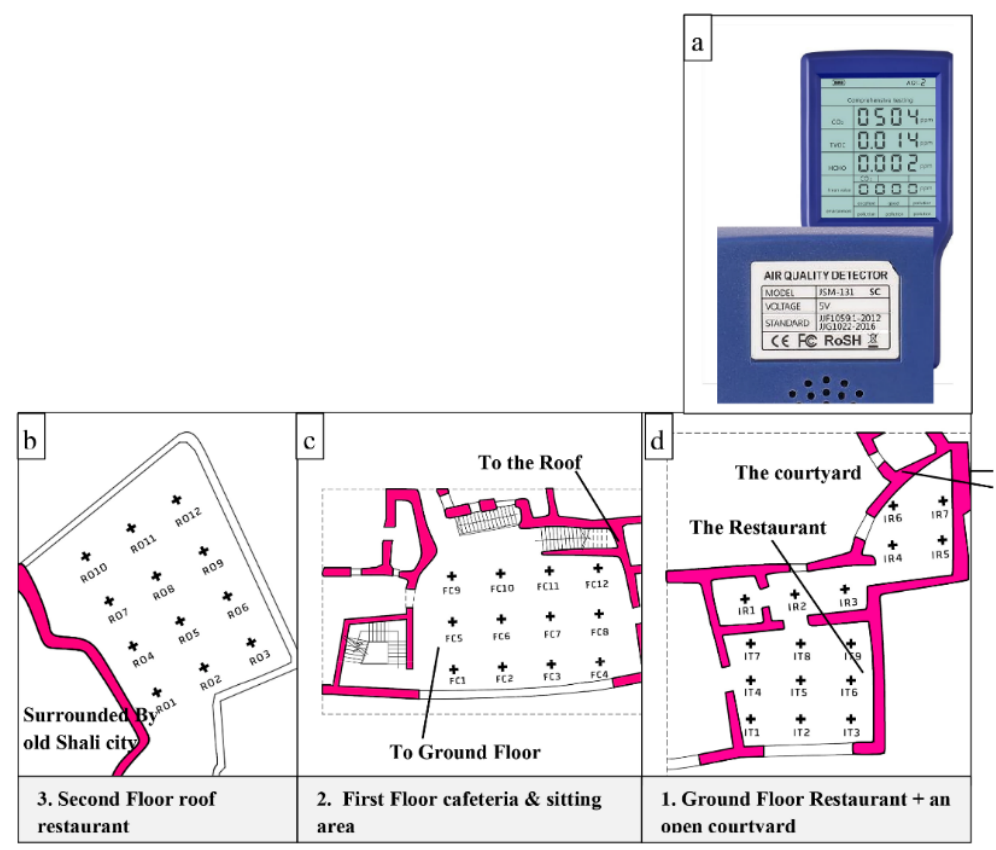

Figure 5: (a) Air quality detector used by the researcher in Babenshal eco-lodge; and (b)(d) Coding tracing points for Babenshal internal spaces: Ground, first and second floors. (Source: Authors.)

although the good cross ventilation occurred in this place (due to the wide window a crossed to the narrow stairs), on other hand the roof restaurant on the roof carries the lowest $\mathrm{CO}_{2}$ ppm \%.

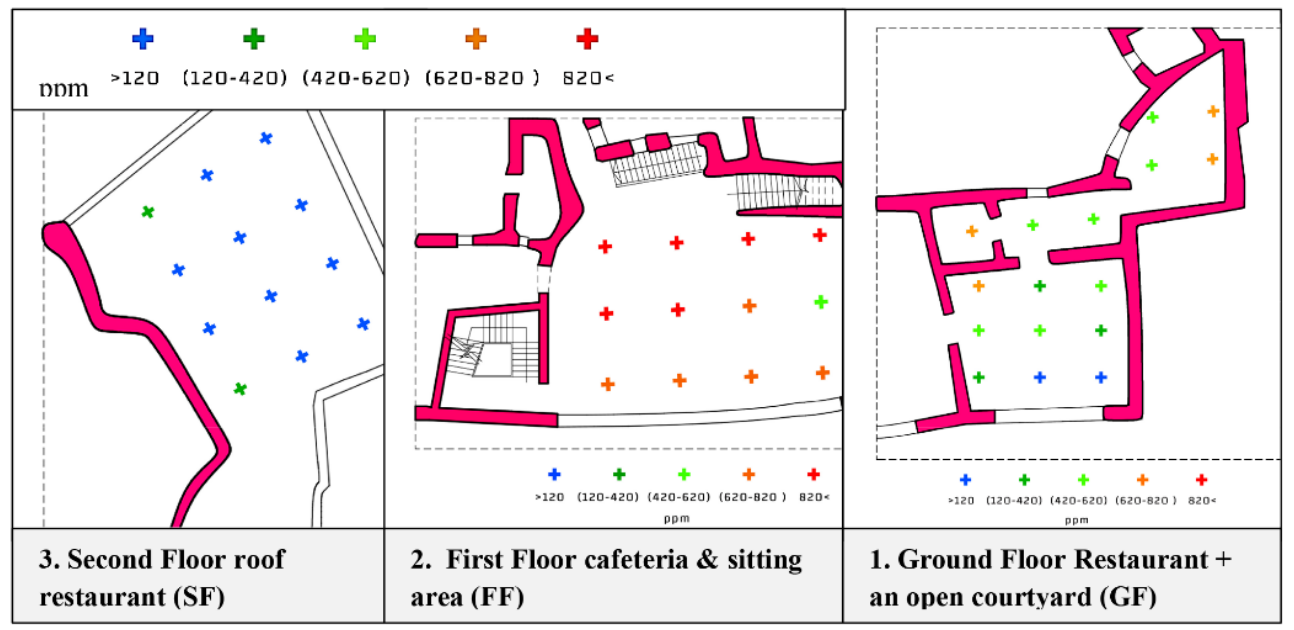

Figure 6: $\quad \mathrm{CO}_{2}$ measurements of ground, first and second floors of Babenshal eco-lodges in ppm. (Source: Authors.) 
- Mean $\mathrm{CO}_{2}$ tracing measurements in Babenshal eco-lodge $=[220$ (Mean of GF $)+637$ $($ Mean of FF $)+170($ Mean of SF) $] / 3=343$ ppm.

\subsubsection{Air speed tracing points $(\mathrm{m} / \mathrm{s})$}

By calculating the average of the measured air flow the researcher found that the minimum value for air flow presented in the first cafeteria floor, while the roof floor carries the highest value. This result can be concluded and easily predicted when tourists visit the place. This is because although the roof is not surrounded by built blocks, it was disappointing that the first floor roof is poorly ventilated and this is contradicting to the aim of the eco-lodge designer which is creating comfortable cross ventilation in this area (see Fig. 7).



Figure 7: Air Flow measurements of Ground, first and second floors of Babenshal ecolodges in m/s. (Source: Authors.)

- Mean air flow tracing measurements in Babenshal eco-lodge $=[0.75($ Mean of GF $)+0.2$ $($ Mean of FF) $+1.2($ Mean of SF) $] / 3=0.72 \mathrm{~m} / \mathrm{s}$.

\subsubsection{Temperature tracing points (degree Celsius)}

The below pictures show that the roof has the highest average temperature relative to the rest of the eco-lodge's floors. This result is variable through the day hours but the aim of the researcher is to identify the mean value of the air quality in each point of the eco-lodge's internal spaces including the roof (see Fig. 8).

- Mean of temperature tracing measurements in Babenshal eco-lodge $=16.5$ [(Mean of $\mathrm{GF})+15($ Mean of FF $)+20.5($ Mean of SF $)] / 3=17.34^{\circ} \mathrm{C}$.

3.5 Calculating the weighting of each value to obtain the credible weighting of the lodge environmentally

In this paper the researcher had only measured and calculated part of the equation that was developed in her paper under the name "Developing an Ecological Assessment Tool for 


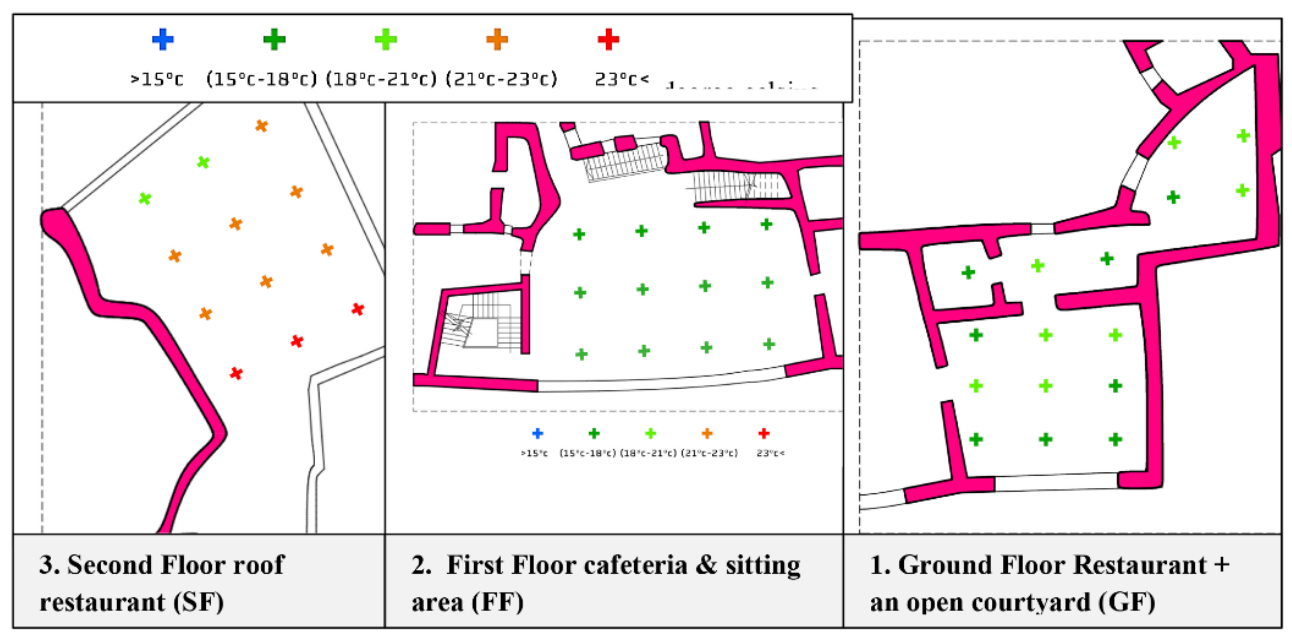

Figure 8: Temperature tracing points and their measurements of ground, first and second floors of Babenshal eco-lodges in m/s. (Source: Authors.)

Siwan eco-lodges in the Egyptian western desert (EWD)" by finding the parameters of the IEQ indicators multiplying them by IEQ weighting coefficient $(0.14)$ to find their real values. Those values are then added to the rest of the Indicators related to gain the real IEQ mean value of Babenshal eco-lodge. Moreover in order to calculate the total Environmental mean quality of the lodge, all Environmental Categories should be added repeating the previous steps for each category.

Each category has its own parameter measuring system in order to gain there values. In this paper the researcher only choose to measure the highest indicators of the IEQ Category.

\section{RESULTS}

This paper is defining the system of finding the results for the criterion equation which is built to serve Siwan eco-lodge in the EWD. This process is complicated and must be accurately defined by the mean required tool that suits the items and categories that were defined in previous researcher papers. In this paper the researcher shows an accurate way that can be used for weighting existed eco-lodges. Moreover the tools used are not suitable to measure unbuilt eco-lodge otherwise computational methods as simulation are suitable in such model. And finally and not last, each Category as Economic Category or Social one has its specific accurate process and thus the researcher is aiming to continue to search for the most suitable way for each Category of the Environmental Aspect to be use in any Siwan eco-lodge in the future.

\section{CONCLUSION AND RECOMMENDATIONS}

- An ecological assessment model is a cyclic process that must be developed and adapt to periodical variations and challenges.

- There must be an intellectual understanding and respect between architects and local labors during their contribution for developing Siwan eco-lodge.

- Nature has the first priority among all phenomena that directly affects Siwan eco-lodges during the total design processes. 


\section{Score of measured Parameter (1 or 0.5 or 0$)$ * Parameter weighting} Coefficient $=$ Parameter Result (of next indicator)

\section{Total result of previous indicator's parameters * Indicator weighting Coefficient $=$ Indicator Result (of next Category)}

1. Mean Babenshal seasonal co2 production (IAQ Indicator) * Indicator weighting $=343 * 0.14=\mathbf{4 8 . 0 2}$.

2. Mean Babenshal seasonal Air Flow (Ventilation quality Indicator)* Indicator weighting Coefficient $=0.72 * 0.14=\mathbf{0 . 1 0 0 8}$

3. Mean of Babenshal seasonal Temperature (Thermal Comfort Indicator $)^{*}$ Indicator weighting Coefficient $=17.34 * 0.14=\mathbf{2 . 4 2 7}$

Total Result of previous Category's Indicator * Category weighting coefficient $=$ IEQ Category result $(C R)$

$(48.02+0.1008+2.427+$ life quality value + Day light + Visual quality Occupant Quality + Safety + Acoustic Control) $* 0.14=$ The real valu of Babenshal IEQ Category.

Final Result of Environmental Assessment Tool $=$ CR (site) + CR (Energy) + CR (Water) +CR (Material) + CR (IEQ) + CR (Waste) + CR (Economic).

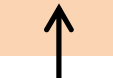

- The weighting process of an eco-lodge in specific Siwan eco-lodges must be accurate and specialized to the required eco-lodge meant to be measured and getting its Environmental or Social real weighting.

- The weighting system is a system built to serve certain eco-lodges of specific location and shouldn't be applied globally to serve its real purpose.

- Scientists and architects are required to visit the eco-lodge and live among local people for a period not less than 3 month in order to conclude and summarize all required data for measuring the real environmental weighting of this eco-lodge.

\section{REFERENCES}

[1] Fakhry, A., Siwa: The Oasis, The American University in Cairo Press: Siwa Oasis, Cairo, 1973. ISBN 9774241231. 
PI-336 Structural Studies, Repairs and Maintenance of Heritage Architecture XVII

[2] Bayoumi, O.A. \& Bayoumi, A.A., Developing an Ecological Assessment Tool for Siwan Eco-lodges in the Egyptian Western Desert (EWD). Wessex Institute: Valencia, Spain, 2020.

[3] Azmi R., Raies, A.H. \& Emad, F., An interview with the architect, construction engineer and the builder of Babenshal Eco-lodge [مقابلة]. Babenshal Ecolodge, Ola Ali Bayoumi \& Amr Ali Bayoumi Recorder: Siwa Oasis, 25 (4.32 pm), Jan. 2021.

[4] Vivian, C., The Western Desert of Egypt, vol. 1, The American University: Cairo, Egypt, 2002. 